\title{
Effects of pulmonary artery banding and retrograde aortic arch obstruction on the hybrid palliation of hypoplastic left heart syndrome
}

\author{
Catriona E. Baker, MRCS, ${ }^{\mathrm{a}}$ Chiara Corsini, MS, ${ }^{\mathrm{b}}$ Daria Cosentino, MS, ${ }^{\mathrm{a}}$ Gabriele Dubini, PhD, \\ Giancarlo Pennati, PhD, ${ }^{\mathrm{b}}$ Francesco Migliavacca, $\mathrm{PhD},{ }^{\mathrm{b}}$ and Tain-Yen Hsia, MD, MSc, ${ }^{\mathrm{a}}$ for the Modeling of \\ Congenital Hearts Alliance (MOCHA) Investigators*
}

\begin{abstract}
Objectives: The hybrid approach achieves stage 1 palliation of hypoplastic left heart syndrome with flow and physiologic characteristics that are different from those of the surgical Norwood circulations. In addition to having branch pulmonary arterial banding regulating the balance between pulmonary and systemic blood flows, coronary and cerebral perfusion are dependent on retrograde flow through the native aortic arch when aortic atresia is present. Accordingly, we used computational modeling to assess the effects of pulmonary artery banding diameter and retrograde aortic arch hypoplasia or obstruction on the hybrid stage 1 circulation, including the influence on systemic and cerebral oxygen deliveries.
\end{abstract}

\begin{abstract}
Methods: A computational modeling technique was used to couple a 3-dimensional geometry of the hybrid palliation with a hydraulic network of the entire circulation based on pre-stage 2 hemodynamics. This validated multiscale approach predicts clinically relevant outcomes, such as flow, pressure, ejection fraction, and oxygen delivery. Simulations with pulmonary artery banding varying between 1.5 and $3.5 \mathrm{~mm}$ were performed. To examine the effects of retrograde aortic arch hypoplasia and obstruction, models of differing aortic arch diameter $(2-5 \mathrm{~mm})$ and isthmus coarctation $(2.5-5 \mathrm{~mm})$ were studied.

Results: Banding the branch pulmonary arteries to $2 \mathrm{~mm}$ led to pulmonary and systemic blood flows closest to 1:1 and produced the highest mixed venous saturation and systemic oxygen delivery. Both cerebral and coronary perfusion decreased markedly when the retrograde aortic arch or the coarctation was less than $3 \mathrm{~mm}$ in diameter. Moreover, flow reversal in the carotid arteries was observed during diastole in all models.

Conclusions: These computational simulations of the stage 1 hybrid palliation for hypoplastic left heart syndrome with aortic atresia suggest that small differences in the degree of branch pulmonary arterial banding can result in significant changes in the overall performance of the hybrid palliation. Furthermore, retrograde aortic arch hypoplasia or obstruction can lead to suboptimal cerebral and coronary perfusion. Precise pulmonary artery banding may be important to optimize interstage physiology in patients undergoing the hybrid approach, and pre-interventional imaging of the aortic arch and isthmus should be performed to rule out potential for postprocedural suboptimal cerebral and coronary perfusion. (J Thorac Cardiovasc Surg 2013;146:1341-8)
\end{abstract}

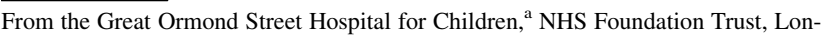
don, United Kingdom; and Laboratory of Biological Structure Mechanics, ${ }^{\text {b Struc- }}$ tural Engineering Department, Politecnico di Milano, Milano, Italy.

This study was supported by a grant from the Fondation Leducq, Paris, France.

Disclosures: Authors have nothing to disclose with regard to commercial support.

* MOCHA Investigators: Andrew Taylor, MD, Alessandro Giardini, MD, Sachin Khambadkone, MD, Marc de Leval, MD, Silvia Schievano, PhD, and T-Y Hsia, MD (Great Ormond Street Hospital for Children, London, UK); Edward Bove, MD, and Adam Dorfman, MD (University of Michigan, Ann Arbor, Mich); G. Hamilton Baker, MD, and Anthony Hlavacek (Medical University of South Carolina, Charleston, SC); Francesco Migliavacca, $\mathrm{PhD}$, Giancarlo Pennati, $\mathrm{PhD}$, and Gabriele Dubini, PhD (Politecnico di Milano, Como, Italy); Alison Marsden, $\mathrm{PhD}$ (University of California, San Diego, Calif); Jeff Feinstein, MD (Stanford University, Stanford, Calif); Irene Vignon-Clementel (National Institute of Research in Informatics and Automation, Rocquencourt, France); Richard Figliola, $\mathrm{PhD}$, and John McGregor PhD (Clemson University, Clemson, SC).

Received for publication July 13, 2012; revisions received Nov 28, 2012; accepted for publication Jan 17, 2013; available ahead of print Feb 22, 2013.

Address for reprints: Tain-Yen Hsia, MD, MSc, Cardiac Unit 7th Floor, Nurses Home, Great Ormond Street Hospital for Children, NHS Trust London, WC1N 3JH, UK (E-mail: hsiat@gosh.nhs.uk).

0022-5223/\$36.00

Copyright (c) 2013 by The American Association for Thoracic Surgery

http://dx.doi.org/10.1016/j.jtcvs.2013.01.038
}

The hybrid procedure for hypoplastic left heart syndrome (HLHS) was introduced in 1993 as an alternative approach to stage 1 palliation. ${ }^{1}$ Similar to the surgical Norwood procedures, the objective of the hybrid palliation is to maintain adequate systemic perfusion and control pulmonary blood flow to achieve optimal systemic, cerebral, and coronary oxygen delivery. However, the hybrid approach achieves these goals through interventional stenting of the ductus arteriosus to provide systemic flow (Qs) and surgical bilateral pulmonary artery (PA) banding to restrict pulmonary flow (Qp). An atrial procedure such as septectomy, or septostomy or stent, is frequently performed to ensure an unobstructed pulmonary venous return. ${ }^{2}$ Therefore, there are important differences in the palliative circulations achieved between the surgical Norwood and the hybrid approach. In the surgical Norwood circulation, Qp is regulated via a systemic-pulmonary shunt, and the right ventricular 


\section{Abbreviations and Acronyms}

CFD = computational fluid dynamics

HLHS $=$ hypoplastic left heart syndrome

LPN = lumped parameter network

PA = pulmonary artery

$\mathrm{Qp} \quad=$ pulmonary flow

Qs $=$ systemic flow

RAAO $=$ retrograde aortic arch obstruction

$3 \mathrm{D}=3$-dimensional outflow tract is reconstructed such that unobstructed systemic and cerebral perfusion occur in an antegrade manner. In the hybrid palliation, balancing Qp:Qs to achieve optimal systemic oxygen delivery through bilateral PA bands can be challenging and may place additional afterload to the systemic right ventricle. Moreover, in variants where aortic atresia or critical aortic stenosis is present, coronary and cerebral perfusion in the hybrid approach would rely on retrograde flow through the aortic arch. In patients with severe aortic arch hypoplasia or aortic isthmus coarctation, there can be insufficient retrograde aortic flow leading to coronary and cerebral malperfusion. ${ }^{3}$

We have previously used a multiscale modeling approach to examine some of the physiologic and hemodynamic differences between the hybrid and the surgical Norwood circulations. ${ }^{4}$ In this study, we further examined the effects of branch PA banding and investigated the influence of retrograde aortic arch obstruction (RAAO) due to arch hypoplasia or isthmus coarctation on cerebral and coronary perfusion.

\section{MATERIALS AND METHODS}

The multiscale modeling method used in this study consists of coupling a 3-dimensional (3D) finite volume model of the anatomic region reconstructed with the hybrid procedure to a zero-dimensional lumped parameter network (LPN) representing the whole circulation outside the treated domain, as described and validated previously. ${ }^{4-8}$ Figure 1 illustrates, as an example, the multiscale model with 2-mm pulmonary bandings, 5-mm ascending aorta and transverse aortic arch diameter, and no coarctation. Multiscale simulations provide detailed fluid dynamics at any part of the anatomic site of interest and both flow and pressure values in the remaining circulatory system. From these values, averaged over a cardiac cycle, it is then possible to calculate physiologic parameters, such as systemic oxygen delivery and single ventricle efficiency, which better describe the hemodynamic effects of the specific hybrid palliation.

\section{Three-Dimensional Models}

Three different sets of 3D rigid-walled models reproducing stage 1 hybrid palliation were developed. The first set comprised 5 models with varying PA banding diameters, ranging from 1.5 to $3.5 \mathrm{~mm}$ with steps of 0.5 $\mathrm{mm}$. Because the hybrid approach does not involve the aortic arch reconstruction, in contrast to the classic Norwood procedures, these models were characterized by a 5-mm aortic arch diameter, without isthmus coarctation, to eliminate the additional effect of RAAO. They are described in detail in a previous study. ${ }^{9}$

In a second set of simulations, ascending aorta and transverse aortic arch diameters were varied from 5 to $2 \mathrm{~mm}$ with steps of $1 \mathrm{~mm}$ to evaluate the fluid dynamic effects in hybrid patients with different degrees of aortic arch hypoplasia. The 4 models were reproduced with a bilateral PA banding fixed to $2 \mathrm{~mm}$, in agreement with simulation results obtained from the first set of models. ${ }^{4,9}$

Last, models with isthmus coarctations of 2.5, 3.0, 4.0, and $5.0 \mathrm{~mm}$ (no coarctation) were simulated with branch PA banding of $2 \mathrm{~mm}$ and aortic arch diameter of $5 \mathrm{~mm}$. Figure 2 shows the 3 sets of 3D models developed in this study.

All models had a fixed 1.6-mm banding length and 7-mm arterial duct diameter. Although some surgeons apply shorter or longer PA bands, the length of the PA band has minimal effect on overall resistance at the branch $\mathrm{PA}$, as shown mathematically in Appendix A, where doubling the banding length results in negligible change in pressure decrease. Likewise, practice variation also exists on the size of the ductal stent during hybrid palliation with reported ductal stent varied from 7 to $10 \mathrm{~mm}$. Dimensions of the 3 brachiocephalic vessels and pulmonary and coronary arteries were the same, obtained from angiograms of a group of patients before stage 2 palliation, as previously described. ${ }^{10}$ Meshes were developed with Gambit (ANSYS, Inc, Canonsburg, Pa) using approximately 160,000 4-node tetrahedral volumetric elements for each computational fluid dynamics (CFD) model, after conducting a mesh sensitivity analysis previously described in detail. ${ }^{7}$ Blood was assumed to be an incompressible Newtonian fluid with density and a dynamic viscosity equal to $1060 \mathrm{~kg} \cdot \mathrm{m}^{-3}$ and $0.005 \mathrm{~kg} \cdot \mathrm{m}^{-1} \cdot \mathrm{s}^{-1}$, respectively.

\section{Lumped Parameter Network}

An identical LPN was coupled to each CFD model. On the basis of the pre-stage 2 clinical data collected from catheterization examinations of 28 patients with HLHS, ${ }^{5,10}$ the LPN described the entire body circulation of a generic child with HLHS with a body surface area of $0.33 \mathrm{~m}^{2}$, outside of the blood volume domain represented by the $3 \mathrm{D}$ models. It comprised 5 subsystems similar to those developed in previous studies of ours: heart, upper and lower systemic circulation, pulmonary circulation, and coronary circulation..$^{4-6,8}$ The heart, the atria, and the single ventricle were modeled with time-varying elastances. A linear resistance was used to represent a nonrestrictive atrial septal defect, whereas the atretic aortic and mitral valves were reproduced by means of nonlinear resistances. ${ }^{11}$

The systemic and pulmonary vascular subsystems were in turn divided into arterial and venous compartments. The intramyocardial pressure acting on the coronary circulation was accounted for with a pressure generator controlled by the single ventricle pressure. The main assumptions regarding the LPN were as follows: pulmonary vascular resistance of $2.3 \mathrm{~mm}$ $\mathrm{Hg} \cdot \mathrm{m}^{2} \cdot \mathrm{L}^{-1} \cdot \mathrm{min}$, systemic vascular resistance of $21.6 \mathrm{~mm}$ $\mathrm{Hg} \cdot \mathrm{m}^{2} \cdot \mathrm{L}^{-1} \cdot \mathrm{min}$, and heart rate of 120 beats $/ \mathrm{min}$. Additional hypotheses were made for the calculation of the oxygen delivery and saturations: hemoglobin value of $16.52 \mathrm{~g} \cdot \mathrm{dL}^{-1}$, oxygen consumption of 156.83 $\mathrm{mL} \cdot \mathrm{min}^{-1} \cdot \mathrm{m}^{-2}$, and pulmonary venous oxygen saturation of $98 \%$.

\section{Multiscale Solution}

In regard to the fluid domain represented by the CFD models described earlier, the mass and momentum conservation equations (ie, the Navier-Stokes equations) were solved with the finite volume method implemented in Fluent (ANSYS, Inc). At the same time, a nonlinear algebraic and ordinary differential equation system resolved the fluid dynamic variables of the LPN. Interface conditions enabled the coupling between the 3D model and the LPN: Uniform time-dependent pressures were imposed at the boundaries of the CFD domain, whereas flow rates averaged over each boundary cross-sectional area were passed to the LPN. ${ }^{8}$ In addition, the local velocity profiles were not forced, but 


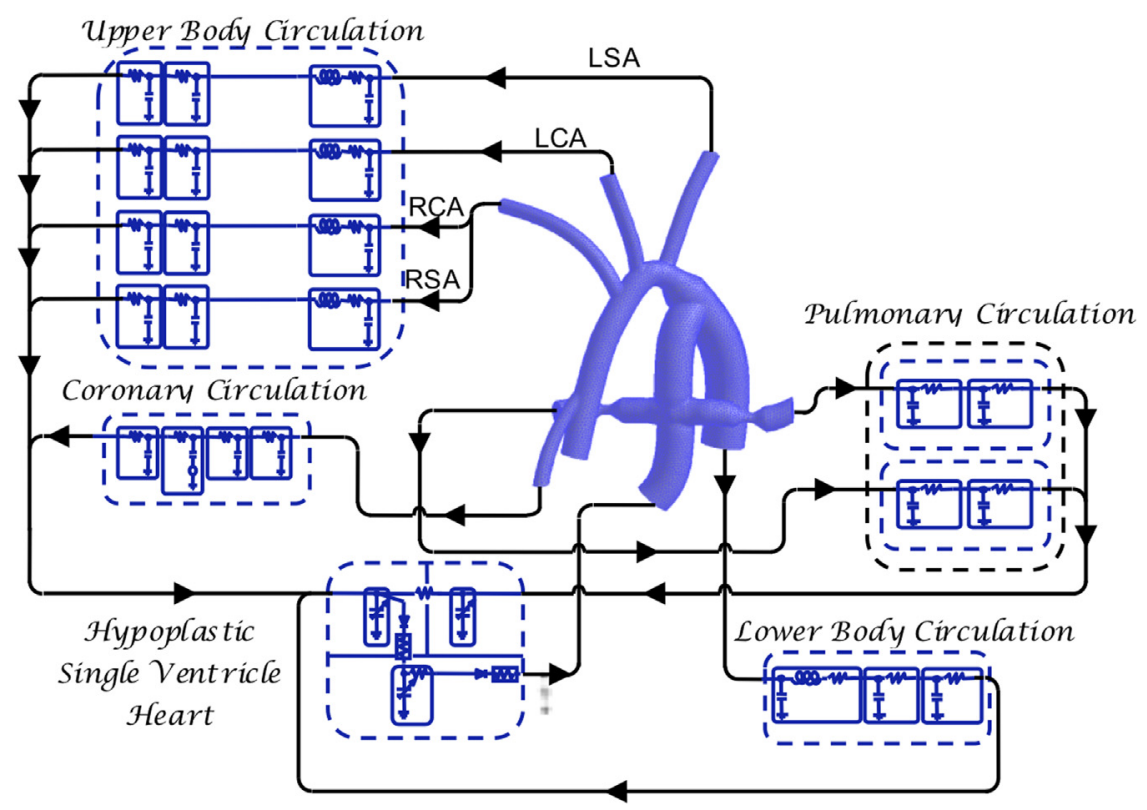

FIGURE 1. Multiscale model of the hybrid Norwood with 2-mm pulmonary bandings, 5-mm ascending aorta and transverse aortic arch diameter, and no coarctation. $L S A$, Left subclavian artery; $L C A$, left carotid artery; $R C A$, right carotid artery; $R S A$, right subclavian artery.

calculated, at each time instant to allow detection of possible reversal flows at the interfaces.

All simulations were carried out on an Intel Core 2 Duo $3 \mathrm{GHz}$ personal computer (Intel Corp, Santa Clara, Calif). To guarantee a stable computational solution, a minimum of 4 cardiac cycles was simulated for each model with a time-step fixed to $10^{-4}$ seconds. The time required for the simulation of 1 cardiac cycle was approximately 12 hours. A segregated solver and the implicit Euler method for time integration were identically applied to the 3D models by means of the fluid dynamic code Fluent (ANSYS, Inc). On the basis of various flows obtained from the simulations, systemic and cerebral oxygen deliveries $\left(\mathrm{mlO}_{2} \cdot \mathrm{min}^{-1} \cdot \mathrm{m}^{-2}\right)$ were calculated as follows ${ }^{4,5}$ :

$$
\begin{gathered}
O_{2}^{s y s} \text { delivery }=\frac{Q_{s} \cdot C_{a r t} O_{2}}{B S A} \\
O_{2}^{c e r} \text { delivery }=O_{2}^{\text {sys }} \text { delivery } \cdot \frac{Q_{c e r}}{Q_{s}}
\end{gathered}
$$

where $Q_{s}$ and $Q_{c e r}$ are the systemic and cerebral volume flow rates and $\mathrm{C}_{\mathrm{art}} \mathrm{O}_{2}$ is the oxygen arterial content. $Q_{c e r}$ is calculated as the sum of the flow rates through the left and right carotid arteries.

\section{RESULTS}

For each model, the multiscale approach provides solutions to both pressure and flow dynamics and to physiologic variables, such as oxygen delivery and cardiac output. Variables derived from the 3D models include pulmonary arterial pressure and flow, coronary arterial flow and perfusion pressure, and Qp:Qs ratio. Cardiac output is the summation of flows between Qs and Qp. Right ventricular performance, including ejection fraction, stroke work, and mechanical efficiency (ratio of stroke work and total mechanical energy), can be evaluated from pressure-volume loops generated by the heart. Moreover, oxygen transport equations, including Equations 1 and 2, can be combined with the multiscale approach, allowing calculations of systemic arterial and mixed venous oxygen saturations, as well as systemic and cerebral oxygen deliveries. Because of the large number of potential variables that can be generated with each simulation, only those that are most clinically relevant are presented. Table 1 summarizes these results from simulations that examined the effects of bilateral PA banding diameters, whereas Table 2 presents those data detailing the influences of aortic arch hypoplasia and isthmus coarctation. In both, results obtained from the reference model (no coarctation, 2.0-mm pulmonary bandings, 5-mm aortic arch) were highlighted. Figure 3 graphically demonstrates the effects of PA banding diameter on Qp and Qs, as well as those on systemic arterial and mixed venous oxygen saturations. Figure 4 shows the influence of aortic arch size and degree of isthmus coarctation on both cerebral and coronary blood flow.

As bilateral PA banding becomes more restrictive, Qp:Qs ratio approached 1.4:1 as the diameter reaches 2.0 $\mathrm{mm}$ (Figure 3 ). The reduction of the distal pulmonary arterial flow and pressure corresponded with higher cerebral and coronary blood flow (Table 1). Consequently, while systemic arterial oxygen saturations became lower, systemic and cerebral oxygen delivery improved, with resultant higher mixed venous saturations. This relationship between oxygen delivery and PA banding size achieved maximal oxygen delivery when the branch PAs were restricted to $2 \mathrm{~mm}$, as further luminal reduction to 1.5 mm led to Qp:Qs less than 1 and worse oxygen delivery. However, to achieve this optimal Qp:Qs and maximal 

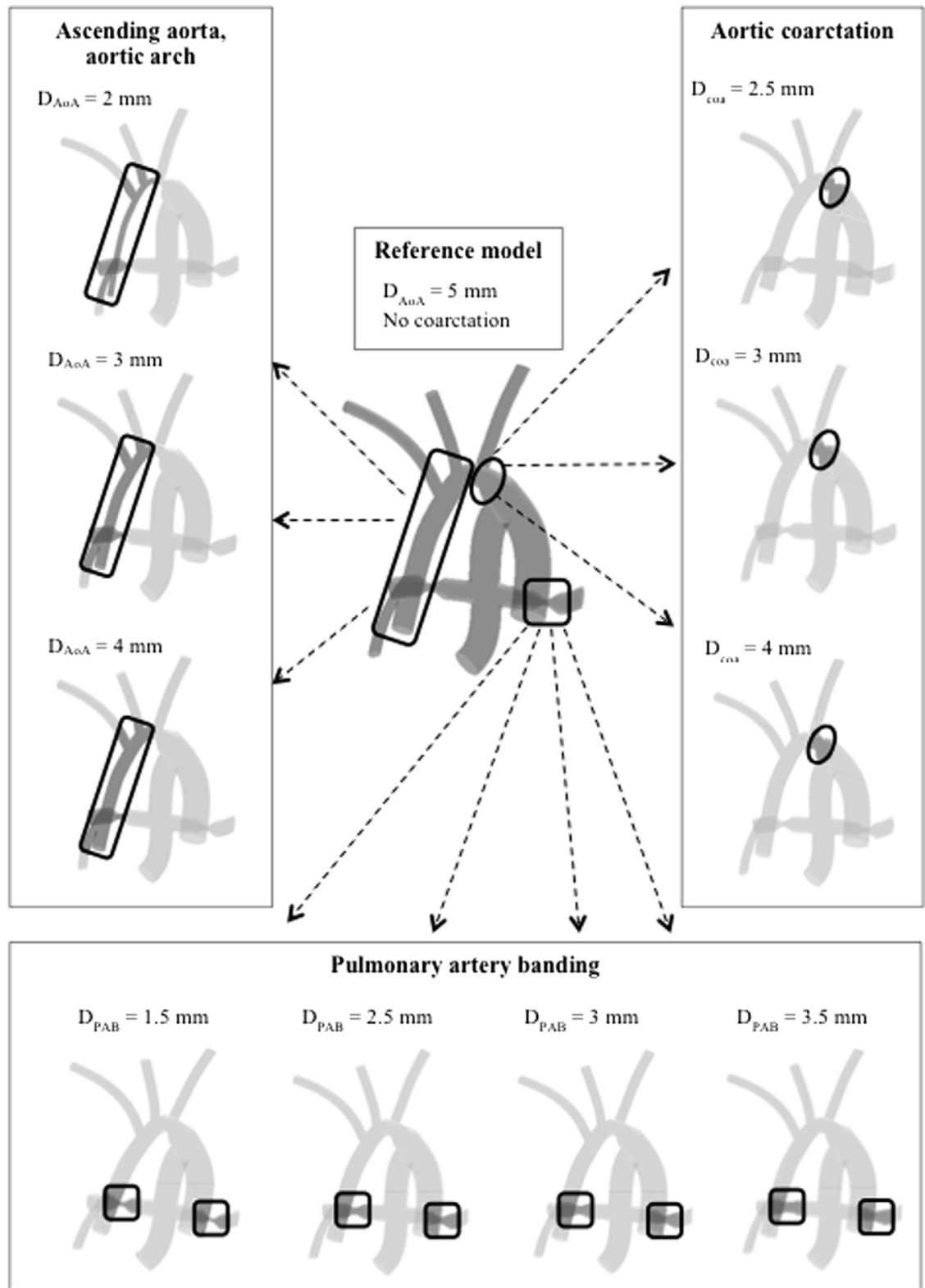

FIGURE 2. Three-dimensional models of the hybrid Norwood operation with varying ascending aorta and aortic arch diameters $\left(l e f t, D_{A o A}\right)$, aortic coarctation diameters (right, $\left.D_{c o a}\right)$, and PA banding diameters $\left(\right.$ bottom, $D_{P A B}$ ). The model considered as a reference is depicted in the center.

oxygen delivery, there is a significant cost to right ventricular performance. The higher afterload associated with restrictive branch PA banding to $2 \mathrm{~mm}$ led to a $20 \%$ decrease in ejection fraction and a $15 \%$ loss in ventricular mechanical efficiency and stroke work when compared with PA banding of $3.5 \mathrm{~mm}$ (Table 1).

By keeping the PA banding diameter at $2 \mathrm{~mm}$, progressively increasing the aortic arch hypoplasia caused a continuous decrease in coronary and cerebral perfusion. A similar observation is noted when isthmus coarctation is stepwise in severity. However, for both scenarios of RAAO, the detrimental effect on cerebral and coronary perfusion was accentuated when the hypoplasia or stenosis became smaller than $3 \mathrm{~mm}$ (Figure 4).
For example, the loss of cerebral blood flow with a 3-mm aortic arch was just 5\% (relative to 5 -mm arch), but soared to $24 \%$ when the arch was at $2 \mathrm{~mm}$. At the same time, decrease in coronary flow reached $25 \%$ in the 2 -mm model versus $6 \%$ in the 3-mm model. Likewise, with a $2.5-\mathrm{mm}$ isthmus coarctation, the resulting losses of coronary and cerebral blood flow (with respect to the no coarctation model) were $25 \%$ and $20 \%$, respectively, compared with $14 \%$ and $9 \%$, respectively, in the 3-mm coarctation model.

\section{DISCUSSION}

The hybrid stage 1 palliation for HLHS is emerging as an alternative to the surgical Norwood procedures. In addition 
TABLE 1. Simulation results with different pulmonary banding diameters (millimeters)

\begin{tabular}{|c|c|c|c|c|c|}
\hline & 1.5 & Reference model & 2.5 & 3.0 & 3.5 \\
\hline PA mean pressure $(\mathrm{mm} \mathrm{Hg})$ & 8.8 & 13.3 & 16.7 & 19.6 & 21.1 \\
\hline Pulmonary blood flow (L/min) & 0.70 & 1.24 & 1.65 & 2.00 & 2.18 \\
\hline $\mathrm{Q}_{\mathrm{p}} / \mathrm{Q}_{\mathrm{s}}$ & 0.7 & 1.4 & 2.2 & 3.2 & 3.8 \\
\hline Cardiac output (L/min) & 1.79 & 2.14 & 2.40 & 2.62 & 2.75 \\
\hline Coronary blood flow (L/min) & 0.076 & 0.064 & 0.054 & 0.046 & 0.042 \\
\hline Coronary mean pressure $(\mathrm{mm} \mathrm{Hg})$ & 71.0 & 61.2 & 54.3 & 46.1 & 43.0 \\
\hline Cerebral blood flow (L/min) & 0.232 & 0.189 & 0.157 & 0.130 & 0.11 \\
\hline Ejection fraction $(\%)$ & 39.3 & 46.1 & 50.9 & 55.0 & 57.6 \\
\hline Ventricular mechanical efficiency & 0.60 & 0.67 & 0.72 & 0.76 & 0.79 \\
\hline Stroke work $(\mathrm{mL} \cdot \mathrm{mm} \mathrm{Hg})$ & 1913.5 & 2187.6 & 2358.3 & 2486.7 & 2554.7 \\
\hline $\mathrm{O}_{2}$ saturation, Mixed venous $(\%)$ & 43.3 & 53.1 & 52.6 & 48.8 & 46.4 \\
\hline $\mathrm{O}_{2}$ saturation, arterial $(\%)$ & 64.8 & 79.2 & 83.8 & 86.3 & 87.3 \\
\hline Systemic $\mathrm{O}_{2}$ delivery $\left(\mathrm{mL} \cdot \mathrm{min}^{-1} \cdot \mathrm{m}^{-2}\right)$ & 471.2 & 475.2 & 421.7 & 361.2 & 335.2 \\
\hline Cerebral $\mathrm{O}_{2}$ delivery $\left(\mathrm{mL} \cdot \mathrm{min}^{-1} \cdot \mathrm{m}^{-2}\right)$ & 101.1 & 100.7 & 88.3 & 75.2 & 69.6 \\
\hline
\end{tabular}

The reference model has 2-mm pulmonary banding, 5-mm aortic arch, and 5-mm coarctation diameters. $P A$, Pulmonary artery; $Q p / Q s$, pulmonary flow/systemic flow.

to avoiding the myocardial dysfunction and instability of systemic and pulmonary vascular resistances associated with neonatal cardiopulmonary bypass and circulatory arrest, the hybrid procedure has other advantages over the surgical Norwood palliation, including providing a pulmonary blood flow that is not dependent on a shunt from the systemic circulation or a right ventricular incision. However, PA banding can accentuate right ventricular afterload and lead to suboptimal myocardial function, and reproducible optimal regulation of pulmonary blood flow through bilateral branch banding remains difficult to achieve. ${ }^{2,12}$ Notwithstanding these differences, the hybrid palliation shared the same objectives as the surgical Norwood procedures: to effective palliate patients with HLHS through the neonatal period with minimal morbidity and mortality, preserving ventricular function, while allowing normal growth and development, especially in the pulmonary vascular bed. Although the question if the hybrid approach should be adopted for all patients with HLHS remains unanswered, we have recently used a sophisticated multiscale modeling approach to highlight some of the hemodynamic and physiologic differences between the hybrid approach and Norwood operations. ${ }^{4}$ In this article, we sought to examine the physiologic effect of bilateral branch PA banding on the hybrid palliation and to assess the influence of aortic arch hypoplasia or isthmus coarctation on coronary and cerebral perfusion when blood flow is obligatorily retrograde through the aortic arch.

These simulation results suggest that, within the PA banding sizes modeled, the best oxygen delivery may be achieved when the branch PA luminal diameter is restricted to $2 \mathrm{~mm}$. It was recognized early on in the hybrid experiences that although ductal patency can be fairly reliably maintained with modern stent technology or prostaglandin,

TABLE 2. Simulation results with various aortic arch and isthmus coarctation diameters

\begin{tabular}{|c|c|c|c|c|c|c|c|}
\hline & \multirow[b]{2}{*}{ Reference model } & \multicolumn{3}{|c|}{ Aortic arch diameter (mm) } & \multicolumn{3}{|c|}{ Coarctation diameter (mm) } \\
\hline & & 4.0 & $\mathbf{3 . 0}$ & 2.0 & 4.0 & 3.0 & 2.5 \\
\hline PA mean pressure (mm $\mathrm{Hg})$ & 13.3 & 13.1 & 13.2 & 13.5 & 13.2 & 13.2 & 13.4 \\
\hline Pulmonary blood flow (L/min) & 1.24 & 1.22 & 1.23 & 1.25 & 1.23 & 1.23 & 1.25 \\
\hline $\mathrm{Q}_{\mathrm{p}} / \mathrm{Q}_{\mathrm{s}}$ & 1.4 & 1.38 & 1.41 & 1.51 & 1.4 & 1.4 & 1.5 \\
\hline Cardiac output (L/min) & 2.14 & 2.10 & 2.10 & 2.08 & 2.11 & 2.09 & 2.09 \\
\hline Coronary blood flow (L/min) & 0.064 & 0.061 & 0.060 & 0.048 & 0.059 & 0.055 & 0.048 \\
\hline Coronary mean pressure $(\mathrm{mm} \mathrm{Hg})$ & 61.2 & 59.0 & 57.5 & 47.3 & 56.7 & 53.1 & 47.3 \\
\hline Cerebral blood flow (L/min) & 0.189 & 0.183 & 0.179 & 0.144 & 0.181 & 0.171 & 0.154 \\
\hline Ejection fraction $(\%)$ & 46.1 & 45.1 & 45.0 & 44.5 & 45.3 & 44.9 & 44.8 \\
\hline Ventricular mechanical efficiency & 0.67 & 0.66 & 0.66 & 0.65 & 0.66 & 0.66 & 0.66 \\
\hline Stroke work $(\mathrm{mL} \cdot \mathrm{mm} \mathrm{Hg})$ & 2187.6 & 2147.9 & 2142.3 & 2127.9 & 2159.2 & 2133.4 & 2127.9 \\
\hline $\mathrm{O}_{2}$ saturation, mixed venous $(\%)$ & 53.1 & 52.2 & 52.1 & 51.1 & 52.3 & 52.0 & 51.4 \\
\hline $\mathrm{O}_{2}$ saturation, arterial $(\%)$ & 79.2 & 78.8 & 79.0 & 79.4 & 79.0 & 78.9 & 79.3 \\
\hline Systemic $\mathrm{O}_{2}$ delivery $\left(\mathrm{mL} \cdot \min ^{-1} \cdot \mathrm{m}^{-2}\right)$ & 475.2 & 465.1 & 460.4 & 441.0 & 462.8 & 458.8 & 444.8 \\
\hline Cerebral $\mathrm{O}_{2}$ delivery $\left(\mathrm{mL} \cdot \min ^{-1} \cdot \mathrm{m}^{-2}\right)$ & 100.7 & 97.0 & 94.6 & 76.9 & 95.8 & 90.6 & 81.8 \\
\hline
\end{tabular}

The reference model has 2-mm pulmonary banding, 5-mm aortic arch, and 5-mm coarctation diameters. $P A$, Pulmonary artery; $Q p / Q s$, pulmonary flow/systemic flow. 
Pulmonary and Systemic Blood Flows vs. pulmonary banding

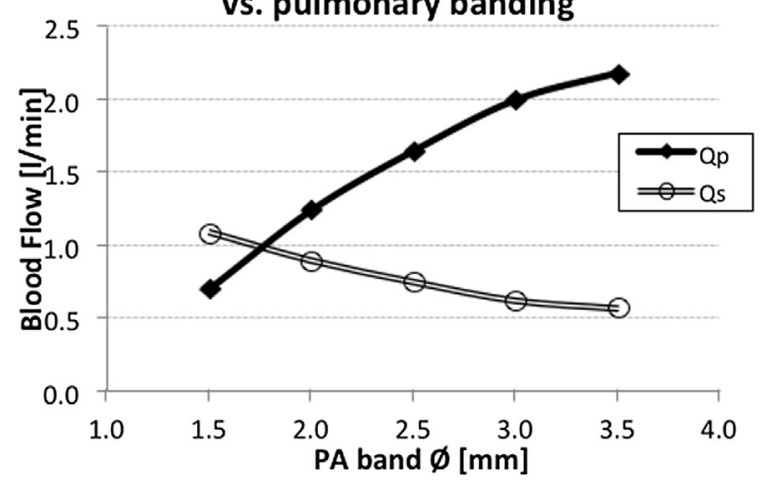

Oxygen Saturations vs. pulmonary banding

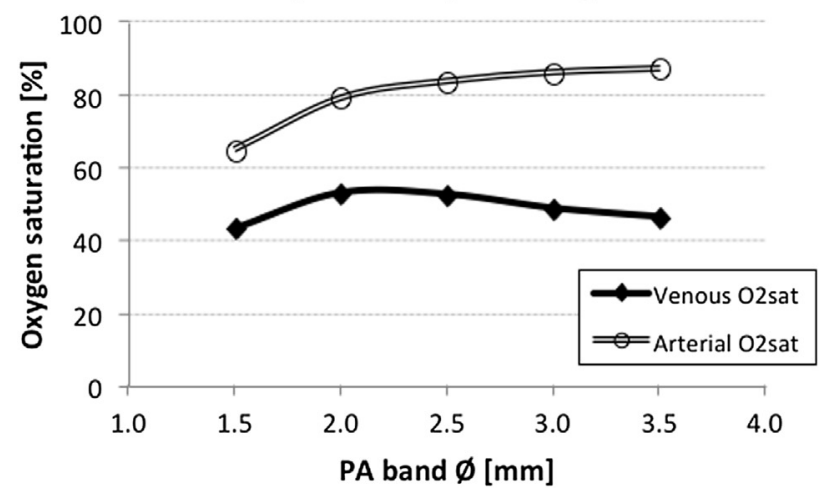

FIGURE 3. Effects of PA banding diameter on Qp/Qs and systemic arterial and mixed venous oxygen saturations. $Q p / Q s$, Pulmonary flow/ systemic flow; $P A$, pulmonary artery.

restricting pulmonary blood flow through bilateral branch PA banding was particularly challenging in patients with HLHS. $^{13,14}$ Indeed, the majority of the high mortality during the "learning curve" period of the hybrid experience was due to pulmonary overcirculation and right ventricular failure. Although several branch PA banding techniques have been described, achieving consistent and optimal pulmonary blood flow restriction remains difficult. This is supported by the wide range of Qp:Qs reported from the Toronto group in patients after the hybrid procedure (0.4-5.7; mean, $1.7 \pm 1.0)$, with a Qp:Qs ratio greater than $2: 1$ in $28 \%$ of the patients and greater than $3: 1$ in $11 \%$ of patients. ${ }^{12}$ Although our data do not provide a technical breakthrough in how to perform the optimal surgical branch PA banding, they do highlight that a small variance in luminal constriction can lead to a great discrepancy in systemic oxygen delivery and ventricular performance.

However, our simulations also demonstrated that incrementally increasing the afterload on the right ventricle by tightening the bilateral PA banding leads to progressively lower ejection fraction and worse ventricular mechanical

\section{Cerebral and Coronary Blood Flows} vs. aortic arch

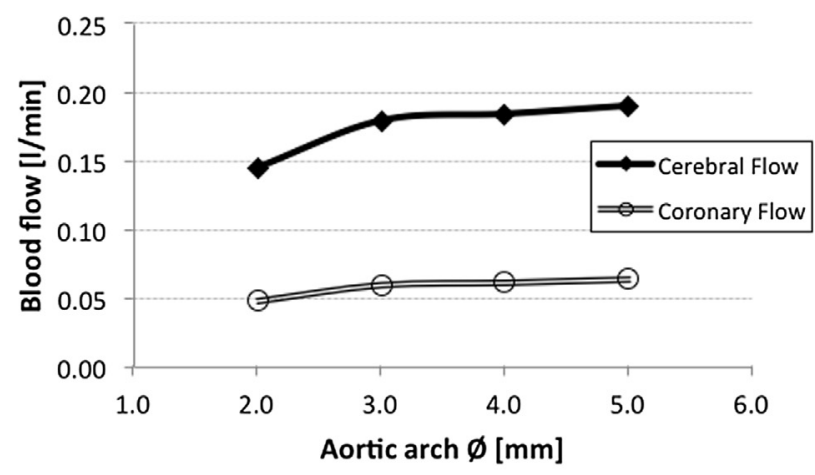

Cerebral and Coronary Blood Flows vs. coarctation

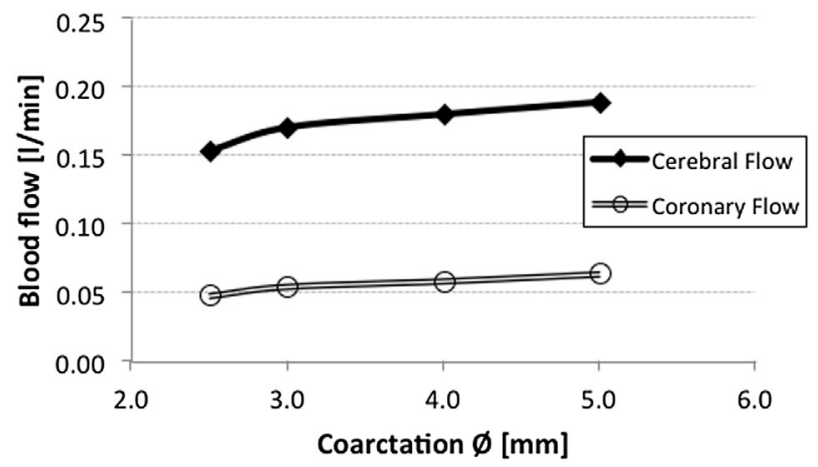

FIGURE 4. Influence of aortic arch size and degree of isthmus coarctation on cerebral and coronary blood flows.

efficiency. The pressure-volume loops generated from the heart component of the multiscale model also predicted progressive loss of stroke work with tighter PA banding. In biventricular animal models, pressure overloading with PA banding can cause right ventricular injury and hypertrophy. Immediately after banding, there is myocardial inflammation and myofibril damage associated with increased expression of cellular adhesion molecules that is associated with myocyte apoptosis. ${ }^{15,16}$ Downregulation of calciumbinding proteins also occurs, and there is decreased mRNA encoding for proteins associated with calcium release, both of which directly have a detrimental effect on myocardial contractility. ${ }^{17,18}$ Taken together, it can be surmised that to achieve the optimal PA banding, balanced Qp:Qs, and maximal systemic oxygen delivery in the hybrid palliation, there is a cost in ventricular performance. Whether this feature of the hybrid palliation has an impact on later ventricular function and outcome after a comprehensive stage 2 or Fontan procedure will require careful examination.

Whereas the surgical Norwood procedures lead to an unobstructed ventricular outflow and antegrade cerebral perfusion, obligatory retrograde aortic arch flow in the 
hybrid palliation due to aortic atresia or severe aortic stenosis can place coronary and cerebral perfusion in jeopardy if there is pre-ductal restriction. RAAO has been realized as an important complication of the hybrid palliation, with an incidence of $10 \%$ to $24 \%$, and, in some centers, pre-intervention recognition of a substrate for obstruction is a contraindication to the hybrid approach. ${ }^{19}$ However, there is no quantitative preoperative guideline to assess whether the potential RAAO warrants abandoning the hybrid approach. Our simulation results suggest that, in addition to isthmus coarctation, severe aortic arch hypoplasia can equally result in cerebral and coronary malperfusion. Moreover, the accentuated loss in cerebral and coronary perfusion when isthmus coarctation or aortic arch hypoplasia is less than $3 \mathrm{~mm}$ would suggest that the influence of RAAO on cerebral and coronary perfusion is not linear. Whether aortic arch or isthmus diameter more than $3 \mathrm{~mm}$ would be safe to proceed with hybrid palliation will require more detailed clinical correlation. However, the simulation results would suggest that caution should be raised on whether to proceed with hybrid palliation when preoperative imaging reveals isthmus narrowing or artic arch hypoplasia less than $3 \mathrm{~mm}$.

It is interesting to observe that the presence of RAAO has little influence on other systemic parameters (Table 2). There is little change in Qp:Qs, because Qs decreases only because of the reduction in cerebral flow as lower body flow is maintained. There are no significant differences in the ejection fraction or ventricular efficiency, and the mixed venous and systemic arterial saturation is not altered. However, this observation does highlight how coronary or cerebral malperfusion may occur underdetected in these patients because of flow reduction despite optimal systemic arterial and venous saturations. Last, we did not model a recent modification proposed by the Toronto group to the hybrid palliation, that is, a shunt between the main PA and the brachiocephalic artery was added to provide additional blood flow into the retrograde aortic arch. ${ }^{20}$ However, a recent modeling study that applied a similar methodology as ours suggests that this reversed modified Blalock-Taussig shunt can ameliorate the reduced cerebral and coronary perfusion when RAAO exists. ${ }^{21}$

Despite the advantages of being able to correlate local pressure and flow effects of hybrid stage 1 palliation with systemic physiologic parameters, the multiscale modeling approach used in this report has some limitations. Present mathematic modeling studies, including ours, remain unable to completely account for biologic adaptation and cardiovascular autoregulation, including the coronary circulation. For example, the effect of cyanosis on myocardial function and vascular tone cannot be simulated. Also, physical growth and the accompanying physiologic maturation are not accounted for. Ventricular adaptation to different volume-loading conditions is not well understood and may variably affect the resulting right ventricular performance acutely and chronically. It should also be noted that we elected to model the ascending aorta and transverse arch with uniform diameters, which may not be the case in all patients with HLHS. Because a wide variation exists in terms of aortic arch dimensions, where differences between ascending aorta and arch are typically small, adopting a uniform dimension in the modeling would have minimal effect on the study focus, which is to highlight the general hemodynamic and physiologic influence of PA banding and RAAO. Last, as complex as they are becoming, mathematic modeling studies such as this remain unable to predict clinical outcome or dictate management decisions. However, they can shed light on some of the relative hemodynamic and physiologic effects of different operative approaches, as demonstrated in this study on the influence on PA banding and RAAO in hybrid stage 1 palliation.

\section{CONCLUSIONS}

These computational results suggest that small differences in the degree of branch pulmonary arterial banding can result in significant changes in the overall performance of the hybrid palliation. To obtain a balanced Qp:Qs and thus optimal systemic oxygen delivery, the heightened afterload produced by the pulmonary arterial banding can lead to worse ventricular function. Furthermore, retrograde aortic arch hypoplasia or obstruction can lead to suboptimal cerebral and coronary perfusion. Precise PA banding may be important to optimize interstage physiology in patients undergoing the hybrid approach, and pre-interventional imaging of the aortic arch and isthmus should be performed to rule out potential for post-procedural suboptimal cerebral and coronary perfusion.

\section{References}

1. Gibbs JL, Wren C, Watterson KG, Hunter S, Hamilton JR. Stenting of the arterial duct combined with banding of the pulmonary arteries and atrial septectomy or septostomy: a new approach to palliation for the hypoplastic left heart syndrome Br Heart J. 1993;69:551-5.

2. Galantowicz M, Cheatham JP, Phillips A, Cua CL, Hoffman TM, Hill SL, et al Hybrid approach for hypoplastic left heart syndrome: intermediate results after the learning curve. Ann Thorac Surg. 2008;85:2063-71

3. Stoica SC, Philips AB, Egan M, Rodeman R, Chisolm J, Hill S, et al. The retrograde aortic arch in the hybrid approach to hypoplastic left heart syndrome. Ann Thorac Surg. 2009;88:1939-47.

4. Hsia TY, Cosentino D, Corsini C, Pennati G, Dubini G, Migliavacca F. Use of mathematical modeling to compare and predict hemodynamic effects between hybrid and surgical Norwood palliations for hypoplastic left heart syndrome. Circulation. 2011;124:S204-10.

5. Bove EL, Migliavacca F, de Leval MR, Balossino R, Pennati G, Lloyd TR, et al. Use of mathematic modeling to compare and predict hemodynamic effects of the modified Blalock-Taussig and right ventricle-pulmonary artery shunts for hypoplastic left heart syndrome. J Thorac Cardiovasc Surg. 2008;136:312-20.e312.

6. Hsia TY, Migliavacca F, Pennati G, Balossino R, Dubini G, de Leval MR, et al. Management of a stenotic right ventricle-pulmonary artery shunt early after the Norwood procedure. Ann Thorac Surg. 2009;88:830-8.

7. Laganà K, Balossino R, Migliavacca F, Pennati G, Bove EL, de Leval MR, et al Multiscale modeling of the cardiovascular system: application to the study of pulmonary and coronary perfusions in the univentricular circulation. $J$ Biomech 2005;38:1129-41. 
8. Migliavacca F, Balossino R, Pennati G, Dubini G, Hsia TY, de Leval MR, et al. Multiscale modelling in biofluidynamics: application to reconstructive paediatric cardiac surgery. J Biomech. 2006;39:1010-20.

9. Corsini C, Cosentino D, Pennati G, Dubini G, Hsia TY, Migliavacca F. Multiscale models of the hybrid palliation for hypoplastic left heart syndrome. $J$ Biomech. 2011;44:767-70.

10. Migliavacca F, Pennati G, Dubini G, Fumero R, Pietrabissa R, Urcelay G, et al. Modeling of the Norwood circulation: effects of shunt size, vascular resistances, and heart rate. Am J Physiol Heart Circ Physiol. 2001;280:H2076-86.

11. Pennati G, Migliavacca F, Dubini G, Pietrabissa R, de Leval MR. A mathematical model of circulation in the presence of the bidirectional cavopulmonary anastomosis in children with a univentricular heart. Med Eng Phys. 1997;19:223-34.

12. Li J, Zhang G, Benson L, Holtby H, Cai S, Humpl T, et al. Comparison of the profiles of postoperative systemic hemodynamics and oxygen transport in neonates after the hybrid or the Norwood procedure: a pilot study. Circulation 2007; 116:I179-87.

13. Chen Q, Parry AJ. The current role of hybrid procedures in the stage 1 palliation of patients with hypoplastic left heart syndrome. Eur J Cardiothorac Surg. 2009; 36:77-83.

14. Takabayashi S, Shimpo H, Kajimoto M, Yokoyama K, Kado H, Mitani Y. Stage I bilateral pulmonary artery banding maintains systemic flow by prostaglandin e1 infusion or a main pulmonary artery to the descending aorta shunt for hypoplastic left heart syndrome. Interact Cardiovasc Thorac Surg. 2005;4:352-5.

15. Carroll SM, Nimmo LE, Knoepfler PS, White FC, Bloor CM. Gene expression in a swine model of right ventricular hypertrophy: Intercellular adhesion molecule, vascular endothelial growth factor and plasminogen activators are upregulated during pressure overload. J Mol Cell Cardiol. 1995;27:1427-41.

16. Ikeda S, Hamada M, Hiwada K. Cardiomyocyte apoptosis with enhanced expression of p53 and bax in right ventricle after pulmonary arterial banding. Life Sci. 1999;65:925-33.

17. Bauer EP, Kuki S, Zimmermann R, Schaper W. Upregulated and downregulated transcription of myocardial genes after pulmonary artery banding in pigs. Ann Thorac Surg. 1998;66:527-31.

18. Matsui H, MacLennan DH, Alpert NR, Periasamy M. Sarcoplasmic reticulum gene expression in pressure overload-induced cardiac hypertrophy in rabbit. Am J Physiol. 1995;268:C252-8.

19. Egan MJ, Hill SL, Boettner BL, Holzer RJ, Phillips AB, Galantowicz M, et al. Predictors of retrograde aortic arch obstruction after hybrid palliation of hypoplastic left heart syndrome. Pediatr Cardiol. 2011;32:67-75.

20. Caldarone CA, Benson LN, Holtby H, Van Arsdell GS. Main pulmonary artery to innominate artery shunt during hybrid palliation of hypoplastic left heart syndrome. J Thorac Cardiovasc Surg. 2005;130:e1-2.

21. Ceballos A, Argueta-Morales IR, Divo E, Osorio R, Caldarone CA, Kassab AJ, et al. Computational analysis of hybrid Norwood circulation with distal aortic arch obstruction and reverse Blalock-Taussig shunt. Ann Thorac Surg. 2012; 94:1540-50.

\section{APPENDIX: EFFECT OF PULMONARY ARTERY BANDING LENGTH}

Proof: "Doubling the length of the PA bands does not have a significant effect on resistance and therefore exerts negligible effect on pulmonary pressure. It is the degree of restriction on pulmonary arterial diameter that regulates the pressure difference."

We may approximately estimate the pressure decrease generated by a pulmonary banding using simple hydraulic formulae describing the flow through a tube of area (A) with a stenosis with a length $\mathrm{L}_{\mathrm{b}}$ and pulmonary banding producing an area $A_{b}$, as depicted in Appendix Figure 1.

The pressure difference $\left(P_{1}-P_{2}\right)$ can be calculated as the sum of the viscous losses along the stenotic length $\mathrm{L}_{\mathrm{b}}$ and losses generated by the abrupt contraction and expansion of the tube:

$$
\left(\mathrm{P}_{1}-\mathrm{P}_{2}\right)=\Delta \mathrm{P}_{\text {visc }}+\Delta \mathrm{P}_{\text {cont }}+\Delta \mathrm{P}_{\text {exp }}
$$

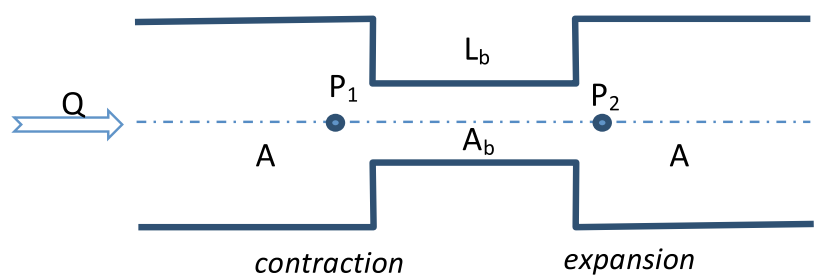

APPENDIX FIGURE 1. Sketch of banding of a pulmonary artery of area (A), banding area $\left(A_{b}\right)$, and banding length $\left(L_{b}\right) .\left(P_{1}\right)$ and $\left(P_{2}\right)$ are the pressures upstream and downstream from the banding, and $(Q)$ is the mean flow rate.

For the sake of simplicity, $\Delta \mathrm{P}_{\text {viscous }}$ can be evaluated with the Poiseuille relation for laminar flow viscous losses:

$$
\Delta P_{\text {visc }}=8 \pi \mu L_{b} \frac{Q}{A_{b}^{2}}
$$

where $\mu$ is the dynamic viscosity and $\mathrm{Q}$ is the mean flow rate.

Pressure losses in contraction and expansion tracts can be described as flow-quadratic terms, in which losses depend on the $A_{b} / A$ ratio (eg, Brater and King ${ }^{1}$ ), namely:

$$
\begin{aligned}
& \Delta P_{\text {cont }}=\frac{1}{2} \rho\left[0.5\left(1-\frac{A_{b}}{A}\right)\right] \frac{Q^{2}}{A_{b}^{2}} \\
& \Delta P_{\text {exp }}=\frac{1}{2} \rho\left[\left(1-\frac{A_{b}}{A}\right)^{2}\right] \frac{Q^{2}}{A_{b}^{2}}
\end{aligned}
$$

We can note that only the $\Delta P_{\text {visc }}$ term depends on $\mathrm{L}_{\mathrm{b}}$.

By assuming a flow rate of $0.6 \mathrm{~L} / \mathrm{min}$ across the banding of $2 \mathrm{~mm}$ and typical properties for the blood $(\mu=0.0035$ $\mathrm{Pa} \cdot \mathrm{s}, \rho=1060 \mathrm{~kg} / \mathrm{m}^{3}$ ), the difference obtained in a pulmonary vessel of $5 \mathrm{~mm}$ in diameter for $\mathrm{L}_{\mathrm{b}}=1.6 \mathrm{~mm}$ or $\mathrm{L}_{\mathrm{b}}=3 \mathrm{~mm}$ is minimal. Indeed, $\Delta P_{\text {visc }}$ is 1.0 and 2.0 $\mathrm{mm} \mathrm{Hg}$, respectively. $\Delta P_{\text {cont }}$ and $\Delta P_{\text {exp }}$ are always 17 and $28 \mathrm{~mm} \mathrm{Hg}$, respectively. Thus, for $\mathrm{L}_{\mathrm{b}}=1.5 \mathrm{~mm}$, $\left(\mathrm{P}_{1}-\mathrm{P}_{2}\right)=46 \mathrm{~mm} \mathrm{Hg}$, whereas for $\mathrm{L}_{\mathrm{b}}=3 \mathrm{~mm},\left(P_{1}-\right.$ $\left.P_{2}\right)=47 \mathrm{~mm} \mathrm{Hg}$.

These calculations indicate that the linear term plays a marginal role with respect to the nonlinear terms in determining the total pressure decrease (1-2 $\mathrm{mm} \mathrm{Hg}$ vs $45 \mathrm{~mm}$ $\mathrm{Hg}$ ). If the banding does not create an abrupt change, but is more gradual, the $\Delta \mathrm{P}$ would slightly decrease, especially for the $\Delta P_{\text {cont }}$ term, but the $\Delta P_{v i s c}$ term that is length dependent would remain nonsignificant.

\section{Reference}

1. Brater EF, King HW. Handbook of Hydraulics for the Solution of Hydrostatic and Fluid-Flow Problems, 6th Ed. New York: McGraw-Hill; 1976. 